\title{
Reactivity of naphtha fractions for light olefins production
}

\author{
Aaron Akah $^{1}$ (1) $\cdot$ Musaed Al-Ghrami $^{1} \cdot$ Mian Saeed $^{2} \cdot$ M. Abdul Bari Siddiqui ${ }^{2}$
}

Received: 9 May 2016/Accepted: 7 November 2016/Published online: 15 November 2016

(c) The Author(s) 2016. This article is published with open access at Springerlink.com

\begin{abstract}
The catalytic cracking of naphtha fractions for propylene production was investigated under high severity catalytic cracking conditions (high temperatures and high catalyst to oil ratio). Straight run naphtha and cracked naphtha along with a with proprietary catalyst were used, and reaction was carried out using a catalyst to oil ratio $(\mathrm{Cl}$ $O)$ of $3-6$ at $600-650{ }^{\circ} \mathrm{C}$ and $1 \mathrm{~atm}$ in a micro activity testing (MAT) unit. The results from this experiments show that light cracked naphtha (LCN) gave the highest propylene yield of $18 \%$ at $650{ }^{\circ} \mathrm{C}$, and that propylene yield depends on the naphtha fraction being used as feed. The trend for reactivity and propylene yield was as follows: light cracked naphtha $>$ heavy straight run naphtha $>$ light straight run naphtha $>$ heavy cracked naphtha.
\end{abstract}

Keywords Naphtha cracking · FCC catalysts - Light olefin production $\cdot$ High severity catalytic cracking

\section{Introduction}

Light olefins such as ethylene and propylene are important building blocks for many end products like polyethylene and polypropylene. Recently, market analysis show that the demand for propylene is outpacing that of ethylene and the current supply cannot match the demand. A large proportion of propylene, about $65 \mathrm{wt} \%$, is produced by steam

Aaron Akah

aaron.akah@aramco.com

1 Research and Development Center, Saudi Aramco, Dhahran 31311, Saudi Arabia

2 Center for Refining and Petrochemicals, Research Institute, KFUPM, P.O. Box 807, Dhahran 31261, Saudi Arabia cracking and about $30 \mathrm{wt} \%$ during the fluid catalytic cracking (FCC) process as by product [1-3]. The propylene to ethylene ratio produced by steam cracking of naphtha is about 0.6 , whereas the ethylene and propylene yields are about 2 and $6 \mathrm{wt} \%$ from conventional FCC process.

During catalytic cracking, the heavier and more complex hydrocarbon molecules are broken down into simpler and lighter molecules by the action of heat and catalyst. It is through this way that heavy oils can be upgraded into lighter and more valuable products (light olefin, gasoline and middle distillate components). The FCC is one of the most catalytic cracking technologies used widely in refinery for producing gasoline and diesel. However, current direction is to maximize olefins such as propylene and butylene by the addition of ZSM-5 to the catalyst formulation [4-14]. ZSM-5 shows high catalytic activity for the cracking of $\mathrm{C}_{7}{ }^{+}$olefins into LPG range olefins and isomerization of n-olefins into i-olefins, while hydrogen transfer (a bimolecular reaction) is not allowed because of its small pore size $[10,15]$. As a result, the entry of large branched hydrocarbons is restricted, thereby making the active sites accessible only to linear and monomethyl molecules [16].

Synergetic effects through mixing of conventional FCC catalyst (mostly USY zeolite) with ZSM-5 additive have been observed by several authors, and show that there is an increase in the yield of light olefins for the catalyst mixture, compared to product yield on the individual catalysts, suggesting that the reaction products are transferred between USY zeolite and ZSM-5 [6, 7, 9, 10, 17, 18]. Improvements in FCC catalyst, process design, hardware, and operation severity can boost high value light olefins yields, with propylene yield that can increase from $6 \mathrm{wt} \%$ up to $25 \mathrm{wt} \%$ or higher with VGO feed. However, additional efforts in the area of catalyst and process 
development are needed to be able to process light hydrocarbon such as naphtha.

Naphtha is the predominant feed for steam crackers, as more than half of the ethylene currently produced worldwide is derived from cracking naphtha feed. However, propylene production from steam crackers depends on the operating rates of the steam cracker and the type of feedstock. The propylene yield from steam cracking is directly proportional to the average molecular weight of the feed [19].

In the past, propylene was produced from steam cracking of naphtha and, as a result, propylene was available in substantial amounts. However, most modern steam crackers use ethane-based feed in place of heavy liquids leading to less propylene [19]. Consequently, it is expected that propylene production from steam crackers will further decrease as a result of the shift to ethane-based feeds. The knock-on effect is that more naphtha will be available as feedstock for the production of propylene via catalytic cracking and this can contribute to reducing the gap between the high demand and low supply of the propylene. The demand for propylene from FCC is growing at a faster rate than global FCC capacity and, therefore, propylene yields from FCC need to increase to keep up with demand.

This paper will discuss the evaluation of naphtha fractions as feedstock for the production of propylene and light olefins via catalytic cracking under high severity conditions which are high temperature and high catalyst/oil $(\mathrm{C} / \mathrm{O}) \mathrm{ra-}$ tio. The catalyst used in this study is made of ZSM-5 and USY in order to draw on the synergetic effect of mixing MFI and FAU zeolites to increase light olefin yield and boost the octane number of the gasoline produced.

\section{Materials and methods}

\section{Naphtha feeds}

Catalytic cracking experiments were carried out using naphtha fraction available at Saudi Aramco Refineries: light straight run naphtha (LSRN), heavy straight run naphtha (HSRN), light cracked naphtha (LCN) and heavy cracked naphtha $(\mathrm{HCN})$. Detailed hydrocarbon analysis (PIONA) of the gasoline-range MAT liquid products was conducted using a Shimadzu PIONA GC equipped with an FID detector. The capillary column used was CP-Sil 5CB (50 m long, $0.32 \mathrm{~mm}$ ID).

\section{Catalyst}

A proprietary catalyst was used for the evaluation of all feedstocks. Prior to testing, the fresh low-activity Y zeolite-based commercial catalyst and ZSM-5-based commercial additive were subjected to hydrothermal deactivation treatment according to ASTM D4463. In a fluidized bed unit (Sakuragi Rikagaku, Japan), catalyst and additive for this study were treated separately in $100 \%$ steam environment at $810^{\circ} \mathrm{C}$ for $6 \mathrm{~h}$. The Y zeolite-based commercial catalyst and ZSM-5-based commercial additive were physically mixed in 3:1 ratio for all the cracking reactions presented in this paper.

\section{Experimental procedure}

Naphtha catalytic cracking was carried out in a fixed-bed micro activity test (MAT) unit (Sakuragi Rikagaku, Japan), using a quartz tubular reactor (I.D. $22 \mathrm{~mm}$, and $38 \mathrm{~cm}$ in length). A schematic representation of the experimental set up is shown in Fig. 1. A low-temperature circulating bath maintained at $-10{ }^{\circ} \mathrm{C}$ was added to the unit instead of using conventional ice water. All experiments were conducted in the MAT unit at $30 \mathrm{~s}$ time-on-stream (TOS). The feed injector and reactor assembly were placed in the heating zone. Before feed injection, the system was purged with $\mathrm{N}_{2}$ flow at $30 \mathrm{~mL} / \mathrm{min}$ for about $15 \mathrm{~min}$. Liquid receiver with the product vial was then connected to the bottom of the reactor. The other end of the receiver was connected to the burette for gas collection. A leak test was performed and a low-temperature bath was raised to cover the liquid receiver. The system was continuously purged with $\mathrm{N}_{2}$ gas for further 15 min. The reactor was charged with a known amount of catalyst and about $1 \mathrm{~g}$ of naphtha was then fed to the reactor during $30 \mathrm{~s}$ along with $30 \mathrm{~mL} / \mathrm{min}$ of $\mathrm{N}_{2}$ flow. After the reaction, stripping of catalyst was carried out for 5 min using $30 \mathrm{~mL} / \mathrm{min}$ of $\mathrm{N}_{2}$ flow. The low-temperature bath was removed and stripping of liquid was continued for three more

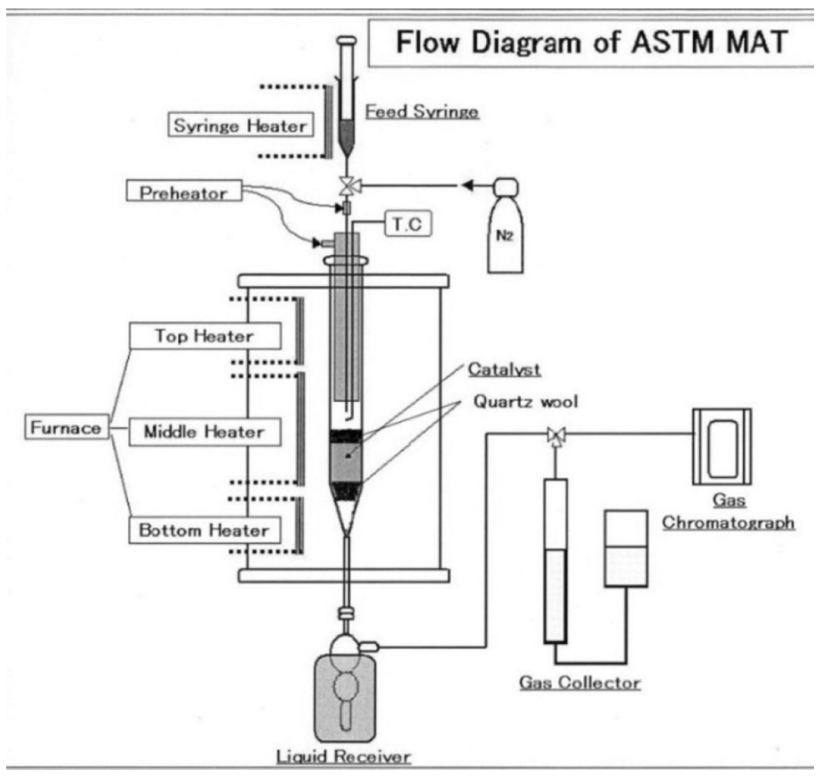

Fig. 1 Schematic diagram of the ASTM MAT Unit 
minutes to remove the gas product dissolved in the liquid. During the reaction and stripping modes, gaseous products were collected in a gas burette by water displacement. Weight of the feed syringe was taken before and after experiments to obtain the exact weight of oil fed. Catalytic cracking experiments were performed at temperatures between 600 and $650{ }^{\circ} \mathrm{C}$ and the effect of catalyst/oil $(\mathrm{Cl}$ $O$ ) ratio for each temperature was studied.

\section{Analysis of MAT products}

MAT products comprised gas, liquid, and coke. Mass balance was considered acceptable within the limits of 95-103 wt \%. A thorough gas chromatographic analysis of all MAT products was conducted to provide detailed yield patterns and information on the performance of the feed being tested. Gases were analyzed using two Varian GCs equipped with Flame Ionization Detector (FID) and Thermal Conductivity Detector (TCD). This allowed the quantitative determination of all light hydrocarbons up to $\mathrm{C}_{4}, \mathrm{C}_{5}$ paraffins, hydrogen and fixed gases. Hydrocarbons from $\mathrm{C}_{1}$ to $\mathrm{C}_{4}$, and $\mathrm{C}_{5}$ paraffins, could be determined accurately. After gas analysis, the weight of each gas component was added and the weight of all components heavier than $\mathrm{C}_{4}$ was added to gasoline fraction. The detailed composition of the product was obtained from the gas analysis which was normalized to account for the differences in mass.

Coke on spent catalyst was determined by Horiba Carbon-Sulfur Analyzer Model EMIA-220 V. About $1 \mathrm{~g}$ of spent catalyst (with tungsten and tin added as combustion promoters) was burnt in the high temperature furnace. The resulting combustion gas $\left(\mathrm{CO}_{2}\right)$ was passed through an Infra-Red Analyzer and carbon content was calculated as a percent of catalyst weight. All the results in this work are presented as weight percent (wt\%) of the product. The conversion of naphtha feeds is defined as the total yield of the hydrocarbons from $\mathrm{C}_{1}$ to $\mathrm{C}_{4}$, hydrogen and coke.

$$
\begin{aligned}
& \text { Naphtha conversion }(w t \%)=\text { Yield }(w t \%) \text { of total gas } \\
& + \text { coke }(w t \%) .
\end{aligned}
$$

The terms and definitions used in this work are summarized in Table 1.

\section{Results}

\section{PIONA Analysis of Naphtha Feeds}

Detailed hydrocarbon (PIONA) analysis of naphtha feeds is presented in Table 2. This table indicates that LSRN was mainly a mixture of pentanes and hexanes $\left(\mathrm{C}_{5}\right.$ and $\mathrm{C}_{6}$ paraffins) which make up about $94 \mathrm{wt} \%$ of the feed. The remaining $6 \%$ was made up of naphthenes and there were no aromatics in LSRN. It also shows that about $69.9 \mathrm{wt} \%$ of the HSRN feed consisted of paraffins, while the remaining portion of HSRN was almost equally distributed between naphthenes (14.4\%) and aromatics (15.7\%). While LCN feed is mainly a mixture of iso-paraffins, olefins and aromatics, $\mathrm{HCN}$ feed consists predominantly of aromatics compounds.

\section{Screening of naphtha feeds}

The naphtha fractions were initially screened at $650{ }^{\circ} \mathrm{C}$, using a $C / O$ ratio of 6 to determine the reactivity for light olefin production. The results are summarized in Table 3. It can be seen that the conversion of $\mathrm{HCN}$ was very low compared to the other three types of naphtha. Similar trends were also observed for total light olefin yield and LPG olefin. However, the coke yield on HCN was much higher than that on all the other naphtha fractions. The low reactivity of $\mathrm{HCN}$ and its tendency to produce more coke can be attributed to its high aromatics content.

Using the $\mathrm{C} / O$ of 6 , the naphtha fractions were further screened at lower temperatures and the results are summarized in Fig. 2 below.

Figure 2 shows that while conversion increased with increasing temperatures for different naphtha fractions, conversion of $\mathrm{HCN}$ had insignificant increase. A similar trend was observed for propylene yield. Based on the screening results, which showed that $\mathrm{HCN}$ was the least reactive feed, it was decided not to conduct further study with HCN feed. The low reactivity and high coke yield of $\mathrm{HCN}$ are attributed to the fact that HCN is made up of predominantly aromatics which are highly stable and difficult to convert and they also act as coke precursors. The hydrocarbon composition of each feed affects it reactivity and it has been shown that a feed that is high in paraffin and aromatic content shows low reactivity during catalytic cracking, while a feed rich in olefins is very reactive.

For LSRN, HSRN and LCN, detailed cracking patterns were obtained by varying $C / O$ ratios in the range of 3-6 at selected temperatures of 600,625 and $650{ }^{\circ} \mathrm{C}$.

\section{Catalytic cracking of LSRN and HSRN}

Figure 3 shows the change in conversion with increasing $C / O$ from 3-6 at different temperatures for both LSRN and HSRN. Both feeds showed an increasing trend in conversion with increase in temperature. HSRN showed higher conversion when compared to that of LSRN because it has less thermal stability than the LSRN. For LSRN, the increase in conversion with the increase in temperature 
Table 1 Definition of terms used in the estimation of performance

\begin{tabular}{ll}
\hline Term & Description \\
\hline Naphtha Conversion & All non-condensable components in the product + coke $\left(\mathrm{H}_{2}, \mathrm{C}_{1}-\mathrm{C}_{4}\right.$ hydrocarbons and coke) \\
Dry gas & $\mathrm{H}_{2}, \mathrm{C}_{1}$ and $\mathrm{C}_{2}$ and $\mathrm{C}_{2}=$ \\
LPG & All $\mathrm{C}_{3}$ and $\mathrm{C}_{4}$ hydrocarbons (paraffins + olefins $)$ \\
Light olefins & All olefins in $\mathrm{C}_{2}-\mathrm{C}_{4}$ range \\
LPG olefins & Propylene + total butylenes \\
$\%$ Yield & Percentage of respective product based on total feed \\
$\%$ Selectivity & Percentage of respective product in the converted feed only \\
\hline
\end{tabular}

Table 2 Composition of naphtha feeds

\begin{tabular}{|c|c|c|c|c|c|c|c|}
\hline & Component/wt $\%$ & $N$-Paraffins & iso Paraffins & Olefins & Naphthenes & Aromatics & Total \\
\hline \multirow[t]{4}{*}{ LSRN } & C-5 & 29.8 & 8.2 & & 2.3 & & 40.3 \\
\hline & C-6 & 26.9 & 28.5 & & 3.7 & & 59.1 \\
\hline & $\mathrm{C}-7$ & & 0.6 & & & & 0.6 \\
\hline & Total & 57.3 & 36.7 & & 6.0 & & 100.0 \\
\hline \multirow[t]{8}{*}{ HSRN } & C-6 & 4.8 & 1.5 & & 2.2 & 0.3 & 8.7 \\
\hline & $\mathrm{C}-7$ & 11.4 & 8.5 & & 5.5 & 2.5 & 27.9 \\
\hline & C-8 & 10.0 & 9.4 & & 3.3 & 6.4 & 29.1 \\
\hline & C-9 & 7.0 & 8.6 & & 2.7 & 5.0 & 23.2 \\
\hline & C-10 & 2.8 & 3.6 & & 0.6 & 1.3 & 8.4 \\
\hline & C-11 & 0.9 & 1.1 & & 0.1 & 0.1 & 2.3 \\
\hline & C-12 & 0.2 & 0.1 & & & & 0.3 \\
\hline & Total & 37.0 & 32.9 & & 14.4 & 15.7 & 100.0 \\
\hline \multirow[t]{6}{*}{ LCN } & $\mathrm{C}-4$ & & & 0.6 & & & 0.6 \\
\hline & C-5 & 4.5 & 24.7 & 22.2 & 1.6 & & 53.1 \\
\hline & C-6 & 1.5 & 9.4 & 4.2 & 3.5 & 11.8 & 30.4 \\
\hline & $\mathrm{C}-7$ & 0.8 & 2.9 & 0.9 & 3.7 & 6.7 & 14.9 \\
\hline & C-8 & & 0.5 & 0.3 & 0.18 & & 1.0 \\
\hline & Total & 6.8 & 37.5 & 28.2 & 9.0 & 18.5 & 100 \\
\hline \multirow[t]{9}{*}{$\mathrm{HCN}$} & $\mathrm{C}-5$ & 0.2 & 1.5 & 1.1 & 0.1 & & 2.9 \\
\hline & C-6 & 0.1 & 0.4 & 0.5 & 0.2 & & 1.2 \\
\hline & C-7 & & & & 0.1 & 20.7 & 20.8 \\
\hline & C-8 & 0.3 & 1.0 & 1.3 & 0.6 & 33.0 & 36.2 \\
\hline & C-9 & 0.3 & 1.5 & 0.3 & 0.6 & 23.4 & 26.0 \\
\hline & C-10 & 0.3 & 2.1 & 0.1 & 0.2 & 6.0 & 8.6 \\
\hline & C-11 & 0.2 & 2.1 & & 0.1 & 1.6 & 3.9 \\
\hline & C-12 & & 0.2 & & & & 0.2 \\
\hline & Total & 1.4 & 8.8 & 3.3 & 1.9 & 84.6 & 100.0 \\
\hline
\end{tabular}

from $625^{\circ} \mathrm{C}$ to $650{ }^{\circ} \mathrm{C}$ was more pronounced compared with the increase in conversion from 600 to $625^{\circ} \mathrm{C}$. This is probably because the hydrocarbon molecules undergo further cracking at $650{ }^{\circ} \mathrm{C}$ than when the temperature is $625^{\circ} \mathrm{C}$ or $600{ }^{\circ} \mathrm{C}$. Dry gas yield showed an increasing trend with conversion at all temperatures for both LSRN and HSRN. The rate of increase in dry gas with conversion is higher for the LSRN feed. For both LSRN and HSRN, total light olefins $\left(\mathrm{C}_{2}=+\mathrm{C}_{3}=+\mathrm{C}_{4}=\right)$ yield showed a linear trend with increasing conversion at all temperatures, whereas HSRN showed higher total light olefins than LSRN.

Figure 4 shows the trend of each of the light olefins yields with conversion. Propylene yield showed a linear trend with increasing conversion at all temperatures for both LSRN and HSRN. HSRN showed higher propylene yields when compared to those of LSRN, because HSRN is made up of molecules with longer chains which are more reactive than those found in LSRN. Ethylene yields showed an increasing trend with increasing conversion at all 
Table 3 Comparison of naphtha cracking at $650{ }^{\circ} \mathrm{C}$

\begin{tabular}{|c|c|c|c|c|}
\hline Feed & $\mathrm{HCN}$ & LCN & HSRN & LSRN \\
\hline CAT/OIL & 5.98 & 6.04 & 5.71 & 5.95 \\
\hline CONV.(\%) & 14.71 & 40.07 & 34.79 & 26.55 \\
\hline \multicolumn{5}{|l|}{ Yields (wt\%) } \\
\hline Methane & 0.85 & 2.81 & 1.81 & 2.33 \\
\hline Ethylene $\left(\mathrm{C}_{2}=\right)$ & 4.75 & 9.14 & 5.45 & 4.79 \\
\hline Propylene $\left(\mathrm{C}_{3}=\right)$ & 4.78 & 17.75 & 12.94 & 10.12 \\
\hline Coke & 0.79 & 0.07 & 0.66 & 0.70 \\
\hline \multicolumn{5}{|l|}{ Groups } \\
\hline $\mathrm{H}_{2}-\mathrm{C}_{2}$ (Dry gas) incl $\mathrm{C} 2=$ & 6.60 & 13.48 & 9.04 & 9.78 \\
\hline All $\mathrm{C}_{3}-\mathrm{C}_{4}(\mathrm{LPG})$ & 7.32 & 26.53 & 25.09 & 16.08 \\
\hline $\mathrm{C}_{2}=-\mathrm{C}_{4}=($ Total light olefins $)$ & 11.23 & 33.63 & 25.79 & 18.46 \\
\hline $\mathrm{C}_{3}=+\mathrm{C}_{4}=(\mathrm{LPG}$ olefins $)$ & 6.48 & 24.49 & 20.34 & 13.66 \\
\hline $\mathrm{C}_{4}=$ (Butenes) & 1.70 & 6.74 & 7.40 & 3.54 \\
\hline \multicolumn{5}{|l|}{ Selectivities } \\
\hline Dry gas & 44.86 & 33.63 & 25.98 & 36.82 \\
\hline Propylene & 32.49 & 44.28 & 37.19 & 38.12 \\
\hline Coke & 5.36 & 0.16 & 1.89 & 2.64 \\
\hline
\end{tabular}

temperatures for both LSRN and HSRN. Butylenes yield showed a linear trend with increasing conversion at all temperatures for both LSRN and HSRN. HSRN showed higher butylenes yields when compared to those of LSRN. For HSRN, the difference in butylenes yields at 625 and $650{ }^{\circ} \mathrm{C}$ was less pronounced.

\section{Catalytic cracking of LCN}

Figure 5 shows the change in conversion and yield pattern with increasing $C / O$ from 3 to 6 at different temperatures for LCN. At all temperatures, cracked naphtha feed showed an increasing trend in conversion. The conversion at the highest $C / O$ of 6 for temperature $650{ }^{\circ} \mathrm{C}$ was about $31 \%$ more than that at $600{ }^{\circ} \mathrm{C}$. Propylene and ethylene yields showed a linear trend with increasing conversion at all temperatures for LCN feed. Although butylenes yield showed an increasing trend with conversion, this trend was not very sharp at higher temperatures of 625 and $650{ }^{\circ} \mathrm{C}$. Dry gas yield showed an almost linear increase with conversion at all temperatures. Total light olefins $\left(\mathrm{C}_{2}=+\mathrm{C}_{3}=+\mathrm{C}_{4}=\right)$ yield with conversion showed a linear trend with increasing conversion at all temperatures for LCN.

\section{Hydrogen transfer index (HTI) and cracking mechanism ratio (CMR)}

The hydrogen transfer index (HTI) and the cracking mechanism ratio (CMR) for the cracking of the three naphtha fractions are shown in Fig. 6. The HTI describes the degree of hydrogen transfer reaction, which reduces the olefin yield in the products and, in this study, the HTI was measured using the ratio of $\mathrm{C}_{4}=/ \mathrm{C}_{4}$. From Fig. 6, the general trend was that the HTI increased with increasing temperature and, for the same temperature, the HTI decreased with conversion. This is because hydrogen transfer is an exothermic reaction with a slower reaction rate and it is not favored by a high reaction temperature and shorter reaction time, but being a bimolecular reaction, it is promoted by a higher acid site density, which is provided by increasing the $C /$ $O$ ratio $[20,21]$.

The cracking mechanism ratio (CMR), which is defined as the ratio of dry gases (methane, ethane, and ethylene) to isobutane in the gas products, is used to measure the ratio of monomolecular to bimolecular types of cracking, since $\mathrm{C}_{1}$ and $\mathrm{C}_{2}$ are typical products from protolytic cracking, while $\mathrm{iC}_{4}$ is a typical product formed by $\beta$-scission of branched products $[18,22,23]$.
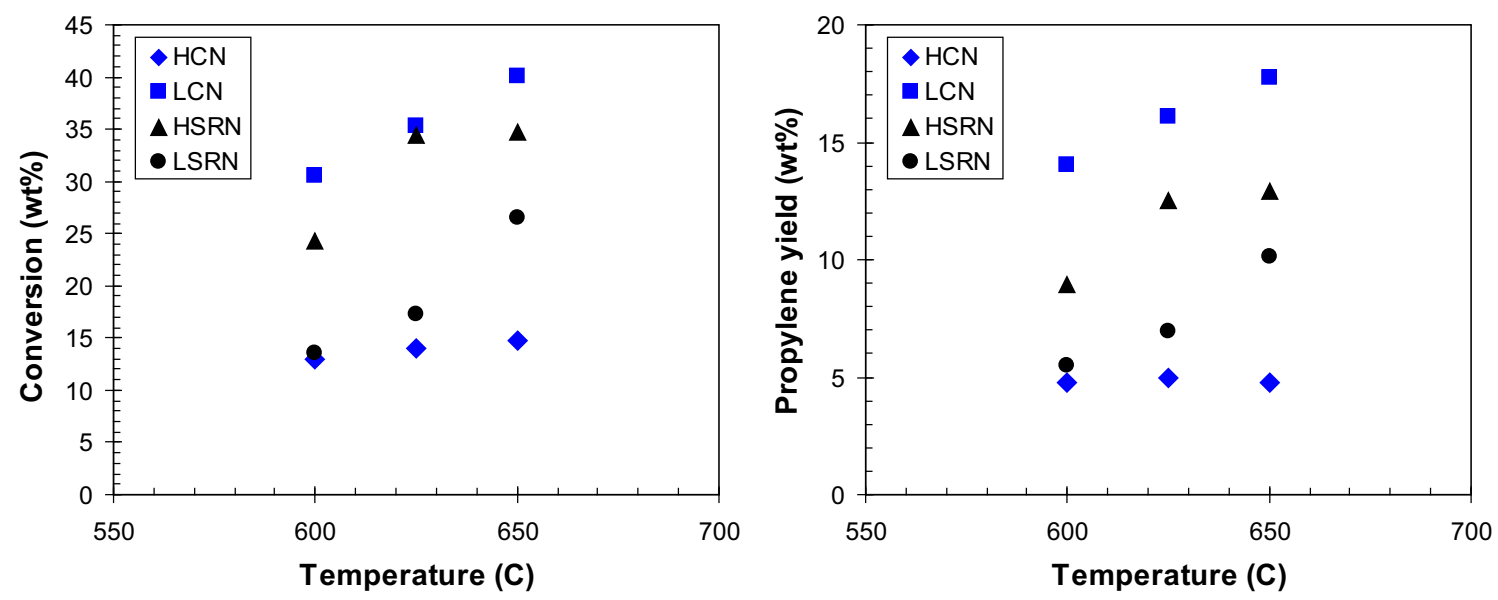

Fig. 2 Impact of temperature on various naphtha feeds cracking at $\mathrm{C} / \mathrm{O}$ of about 6 

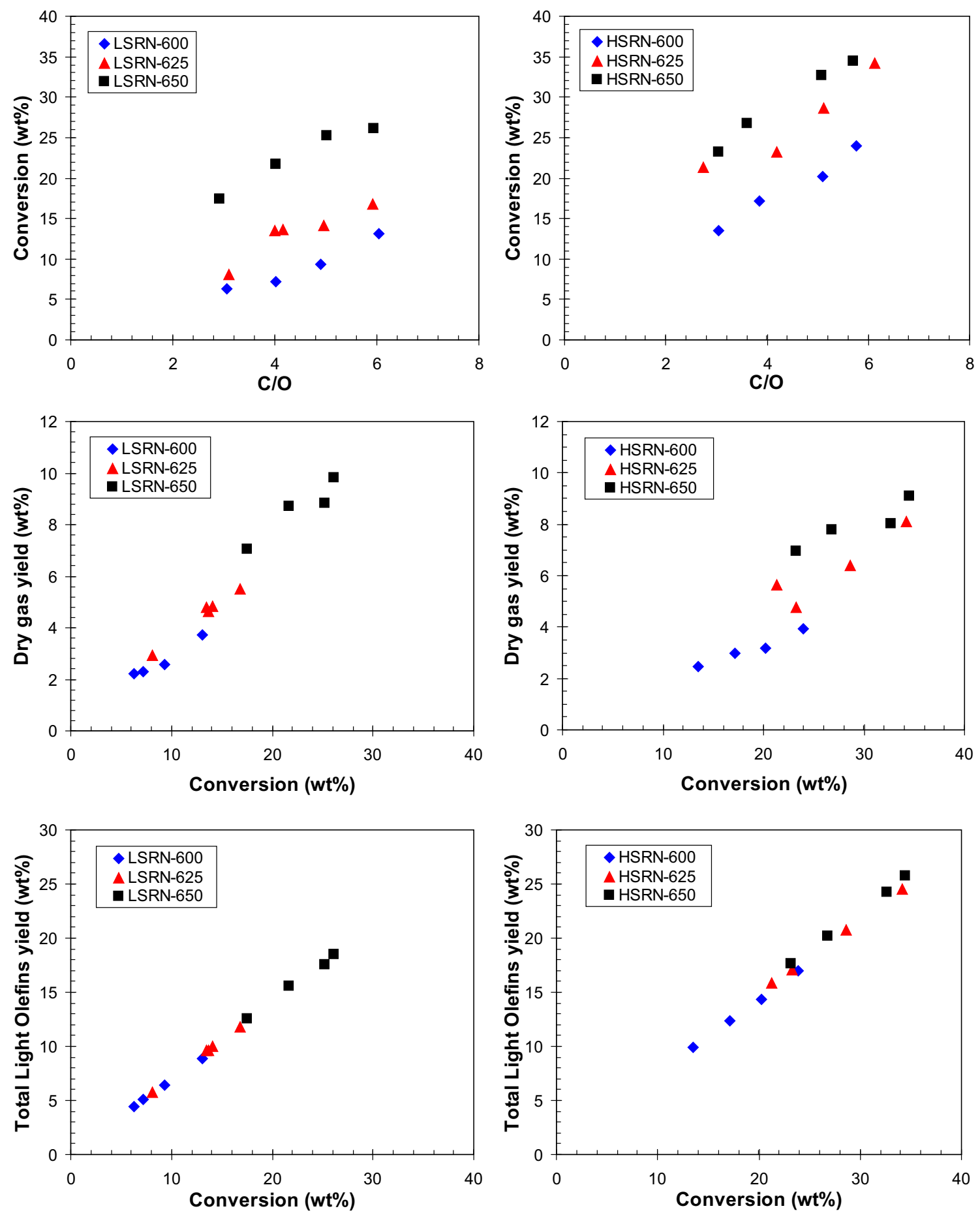

Fig. 3 Conversion and yield data for LSRN and HSRN fractions

A qualitative estimation of the relative importance of the two cracking mechanisms can be made using the cracking mechanism ratio (CMR):

$\mathrm{CMR}=\frac{\left(\mathrm{C}_{1}+\sum \mathrm{C}_{2}\right)}{\mathrm{iC}_{4}}$, where $\mathrm{C}_{1}, \mathrm{C}_{2}$, and $\mathrm{iC}_{4}$ denote the selectivities to methane, ethane and ethylene, and i-butane, respectively.

A high CMR value $(>1)$ reflects an important contribution of the protolytic cracking route, while a low value $(<1)$ indicates the prevalence of the classical $\beta$-scission 

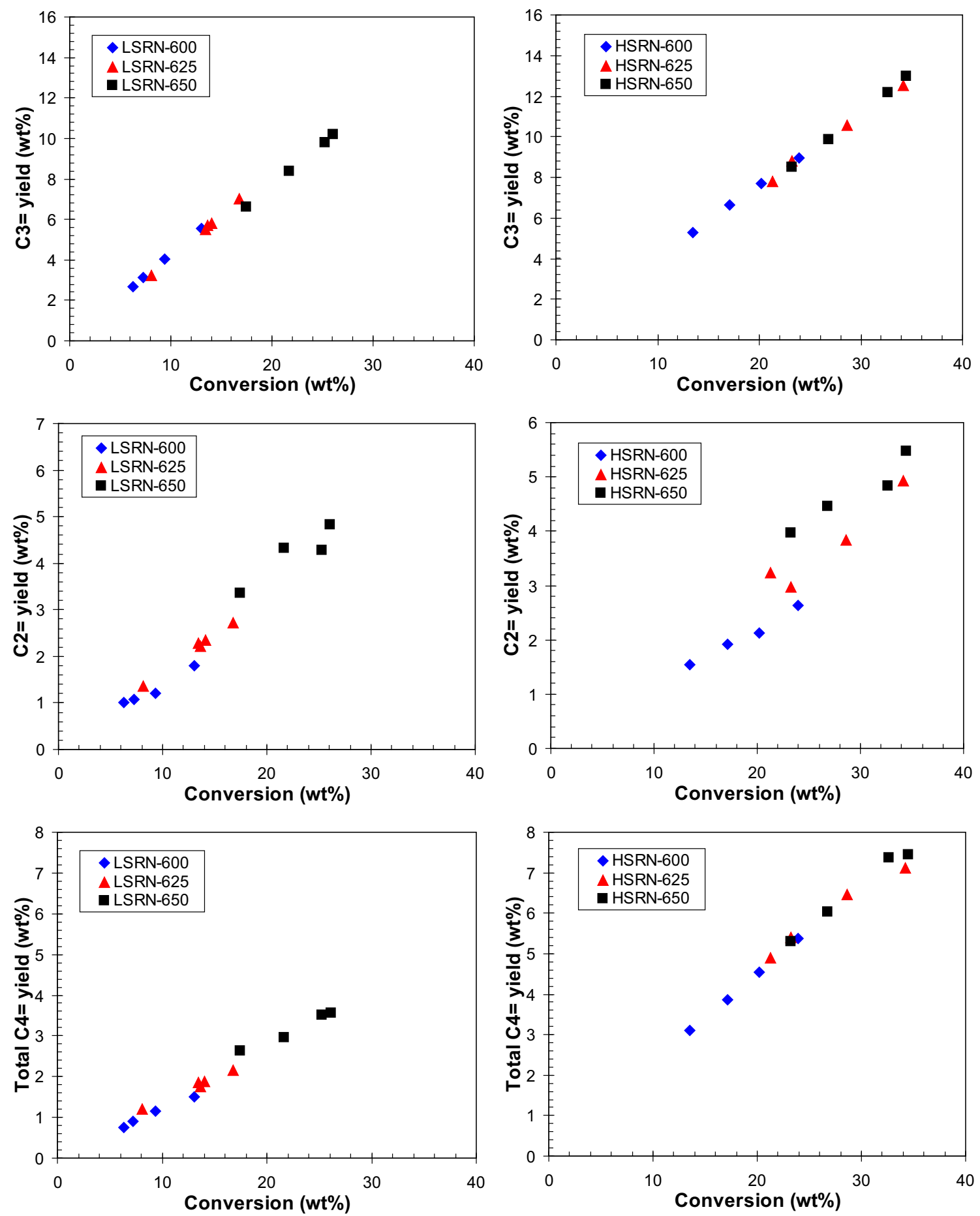

Fig. 4 Light olefins yields of LSRN and HSRN cracking at different temperatures

cracking mechanism. From Fig. 6, it can be seen that the protolytic (monomolecular) cracking mechanism was more predominant than the beta scission (bimolecular) cracking mechanism for all the three naphtha fractions. It was also found that for each reaction temperature, as the conversion increased due to an increase in $C / O$, the CMR decreased as the contribution of the wide pore zeolite was increased. This shows that the production of light olefins is favored when protolytic cracking mechanism becomes dominant over classical bimolecular cracking reactions. 

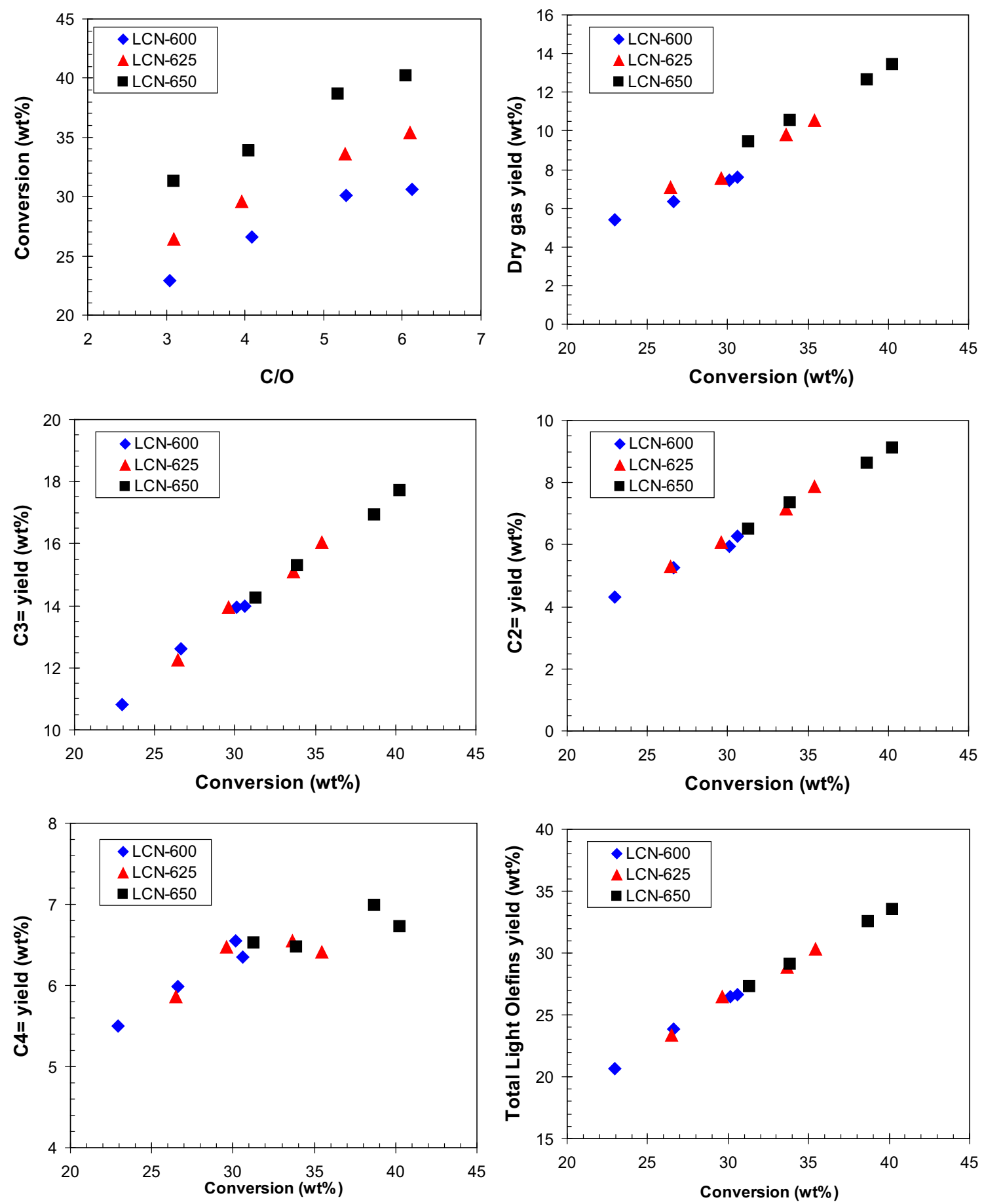

Fig. 5 Impact of increasing $C / O$ on the conversion and yields of $\mathrm{LCN}$ cracking

\section{Thermal cracking index (TCI)}

The contribution of thermal cracking to the cracking of naphtha is illustrated in Fig. 7. The contribution of thermal cracking was measured using the thermal cracking index (TCI), defined as the weight ratio of the sum of $\mathrm{C}_{1}$ and $\mathrm{C}_{2}$ yields to the sum of isobutane and isobutene yields [21].

$\mathrm{TCI}=\frac{\mathrm{C}_{1}+\sum \mathrm{C}_{2}}{\mathrm{iC}_{4}+\mathrm{iC}_{4}^{=}}$ 

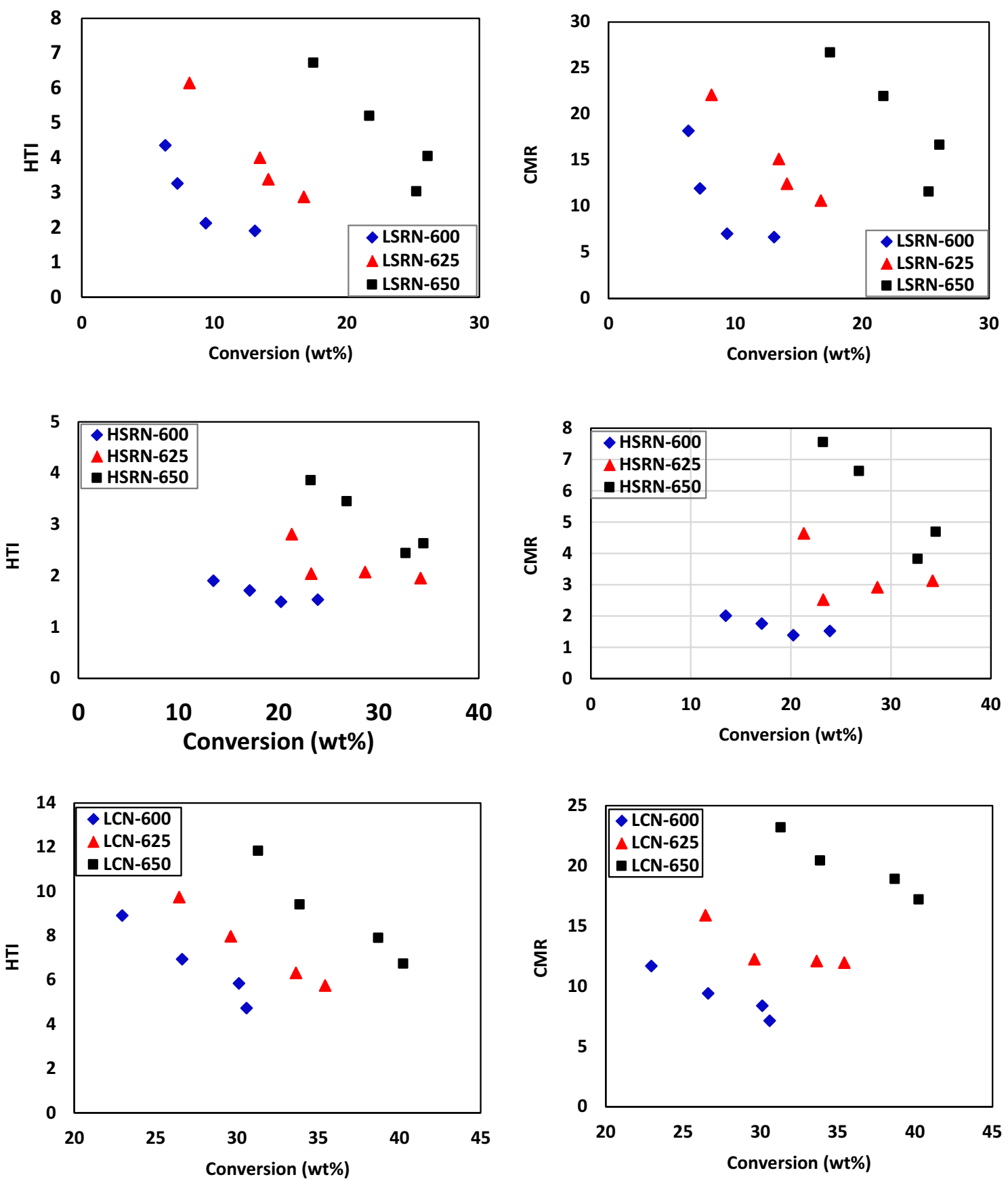

Fig. 6 Impact of temperature on HTI and CMR

A value of TCI $<0.6$ means that catalytic cracking is the main reaction, while a value of $\mathrm{TCI}>1.2$ means that thermal cracking is serious [21].

From Fig. 7, it can be seen that the TCI was much greater than 1 under most conditions indicating that at these temperatures, thermal cracking was serious and as such contributed to the product yield.

The general trend for all three fractions was that TCI increased as the reaction temperature increased. This is

expected because an increase in temperature will lead to more thermal cracking contributions as less stable intermediates undergo further reaction.

\section{Discussion}

The cracking reactions can be categorized into two types, namely catalytic cracking and thermal cracking. Catalytic cracking is endothermic, occurs on the surface of the 

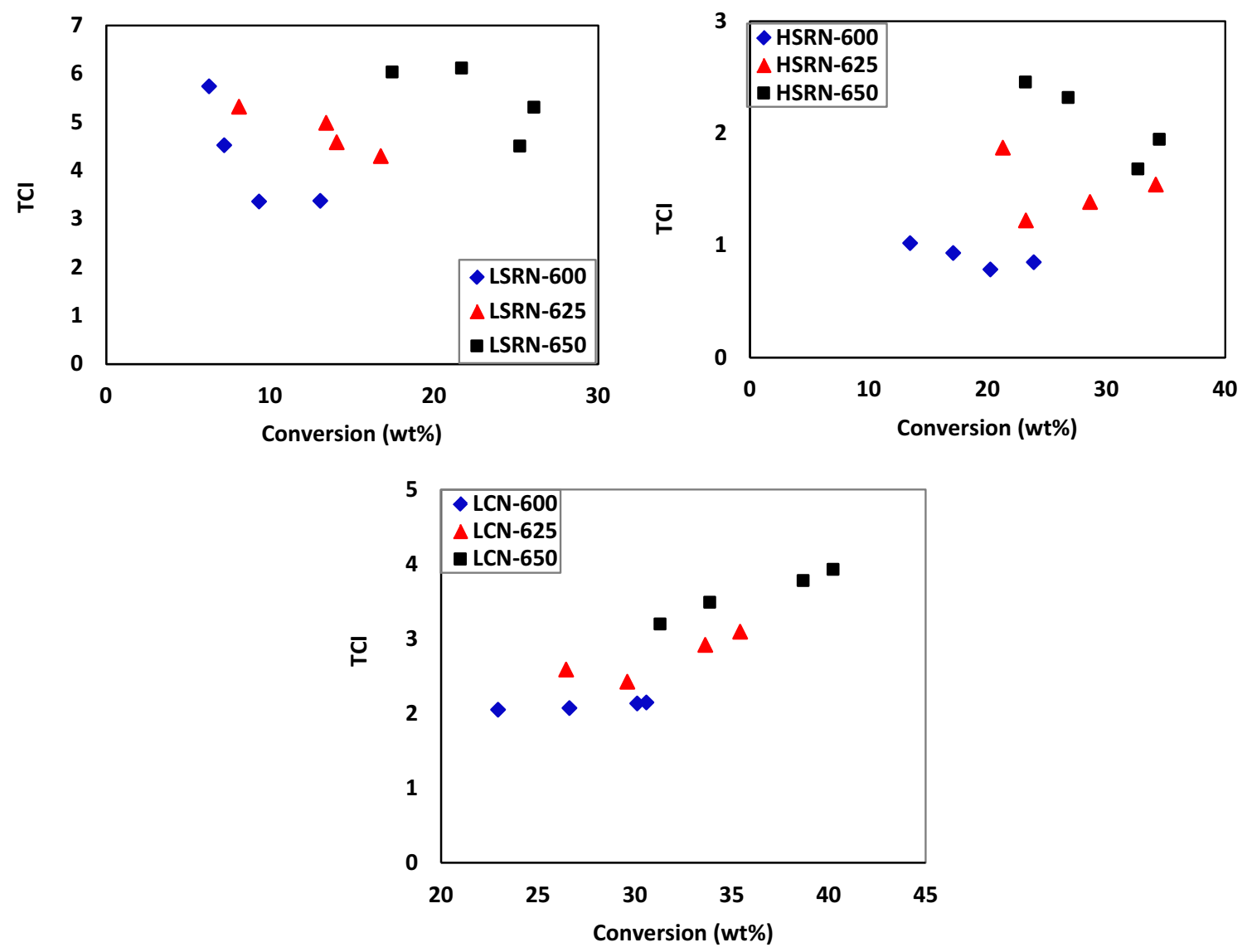

Fig. 7 Effect of temperature on TCI

catalyst and yields high $\mathrm{C}_{3}$ and $\mathrm{C}_{4}$ olefins. So, the reaction temperature and acidic properties of the catalyst play a major role in the activity and selectivity of the reaction. The thermal cracking reaction is also endothermic and follows the free radical mechanism which generates ethylene and dry gas. For increasing propylene production, the reaction conditions have to be optimized to minimize thermal cracking.

The results from this study (Figs. 2, 3, 4, 5) show that reaction temperature, $\mathrm{ClO}$ ratio and feed characteristics have an effect on light olefin yield during catalytic cracking. The yield of light olefins and selectivity to propylene when using $\mathrm{HCN}$ feed are the lowest compared to the other feeds because of its high aromatic content. It has been shown in the literature that hydrocarbon feeds with a high $C / H$ ratio (low hydrogen content) are difficult to convert under FCC conditions [3]. The production of propylene requires a disproportionate share of the hydrogen and co-products such as propane, and dry gas requires an even greater share of hydrogen. Therefore, the amount of hydrogen available from the feedstock can limit the potential to produce propylene. Subsequently, propylene production is highly dependent on feed properties.
In contrast to $\mathrm{HCN}, \mathrm{LCN}$ is the most reactive and shows the highest conversion. It also shows the highest yield for light olefins as well as selectivity. This is because olefins make up a great portion of this feed $(28.5 \mathrm{wt} \%)$, and with the right type of catalyst this can act as intermediate for high yield of light olefins.

LSRN is predominantly $\mathrm{C}_{5}-\mathrm{C}_{6}$ while HSRN is mostly $\mathrm{C}_{6}-\mathrm{C}_{10}$ with much smaller fractions of $\mathrm{C}_{11}-\mathrm{C}_{12}$. Their compositions should explain why HSRN is more reactive than LSRN, because HSRN is made up of longer chain molecules, which are easier to crack than the short length LSRN counterpart. This also has an effect on the product yield, as HSRN shows a higher light olefin yield.

The overall classification in terms of reactivity is as follows: $\mathrm{LCN}>\mathrm{HSRN}>\mathrm{LSRN}>\mathrm{HCN}$.

\section{Influence of catalyst-to-oil ratio on FCC naphtha cracking}

In order for propylene to be produced, the cracking of FCC naphtha has to be carried out at high temperatures, but increasing temperature favors thermal cracking which leads to the formation of dry gas from hydrocarbon [24]. 
Raising the temperature is most effective in controlling the exothermic hydrogen transfer reaction and accelerating the catalytic cracking which is endothermic. In a commercial unit, the high reaction temperature is achieved by raising the catalyst circulation rate. This helps to improve the rate of reaction as well as the propylene yield. Since the hydrogen transfer reaction is a secondary reaction, it is better controlled using a short contact time to limit the hydrogenation of olefin over cracking reactions $[3,8]$.

By increasing $\mathrm{C} / \mathrm{O}$ ratio, contact opportunities between catalyst active centers and hydrocarbon molecules are improved leading to enhanced selectivity and yields of light olefins such as propylene and butylene during catalytic cracking of hydrocarbons.

As can be seen from Figs. 3 and 5, when there is an increase in $\mathrm{C} / \mathrm{O}$, the conversion, total light olefin yield and the yields of dry gas increase. The reactions of olefins take place more easily at high $\mathrm{C} / \mathrm{O}$ due to its high reactivity over catalyst active centers and this explains the high yield of light olefins with LCN as feed. Compared to olefins, paraffins have a lower reactivity towards cracking due to energetically more difficult formation of carbenium ions.

Increasing the catalyst to oil ratio increases the severity of the hydrogenation and cracking reaction leading to over cracking and more saturates. Subsequently, more dry gas is produced, which in this case is made up of mainly methane and ethane. For thermal cracking, free radicals are formed through hydrocarbons splitting their $\mathrm{C}-\mathrm{C}$ bonds and $\mathrm{H}-\mathrm{C}$ bonds, and then inclined to undergoing alpha scission, beta scission, and polymerization to produce $\mathrm{H}_{2}$, methane, ethylene and coke [24]. However, at higher $C / O$, thermal cracking is effectively inhibited as hydrocarbons have more opportunities to contact with active centres of catalysts leading to catalytic cracking. Therefore, the yields of $\mathrm{C}_{1}$ and $\mathrm{H}_{2}$ decrease as the $\mathrm{C} / O$ is enhanced. But because of more small pore-zeolite (ZSM-5) being available at higher $\mathrm{ClO}$, which are more favorable for the formation of ethane, therefore, mostly the yields of ethylene and ethane in dry gas are enhanced. Also, a very high $C / O$ does not necessarily lead to a significant increase of propylene and butylene due to the enhanced hydrogen transfer reaction stemming from the presence of more Y zeolite-based catalyst. As Y zeolite-based catalyst are used in FCC units, the bimolecular mechanism competes with cracking to form light olefins.

For maximizing light olefin production, FCC units should be operated at high severity, which includes high $\mathrm{Cl}$ $O$ ratios, high temperatures, and short contact time to minimize the hydrogen transfer reaction.

It has been well established that the conversion of light hydrocarbons occurs via carbenium ion chemistry $[10,25-27]$ involving the monomolecular and bimolecular mechanisms.
The steps for the catalytic cracking mechanism of alkanes $[10,25,26,28]$ are summarized below and illustrated in Fig. 8:

1. A carbenium ion is first generated by protonation of a paraffin molecule on a Brönsted acid site to form a carbonium ion (a pentacoordinated ion),

2. The carbonium ion then immediately cracks to give a carbenium ion and a paraffin.

3. Then, the carbenium ion cracks to give an olefin and an acidic proton on the surface of the catalyst.

For the Bimolecular mechanism, the carbenium ion in step 3 acts as an active center by reacting with a feed paraffin molecule to form a larger molecule that further cracks according to the following steps:

4. A paraffin reacts with carbenium ion to form a smaller paraffin and a bigger carbenium ion.

5. The bigger carbenium ion then cracks into an olefin and a carbenium ion through beta scission.

The bimolecular mechanism explain the hydrogen transfer reaction and the formation of heavier compounds than those found in the feed such as coke, light cycle oil and heavy cycle oil. Hydrogen transfer reaction usually occurs from an olefin to a carbenium ion on the catalyst surface giving rise to a paraffin and a hydrogen-deficient species (allylcarbenium ion) [29]. The hydrogen-deficient species can be further transformed into aromatics and coke via further dehydrogenation and cyclization reactions. Hydrogen transfer reactions are prevalent at high conversions and help to decrease the selectivity to olefins as shown in Fig. 8.

Thus, a bimolecular cracking mechanism will preferentially lead to the formation of aromatics from the naphthenes, since the carbenium may be directly formed from the feed molecule through a hydride transfer, while a monomolecular cracking mechanism will preferentially lead to short olefins. Then, the balance between hydrogen transfer reactions and cracking reactions will be critical in orienting the selectivity of olefins and naphthenes' conversion towards either propylene or gasoline-range aromatics or paraffins.

The balance between these two mechanisms will depend on the surface coverage by carbenium ions. The presence of carbenium ions is influenced by reaction temperature and catalyst acid site density. The higher number of acid sites favors the bimolecular mechanism. The acid site density may be decreased by dealumination or coking. Catalysts with small pore sizes such as ZSM-5 favor the monomolecular mechanism since there is limited space for the formation of the intermediate species for the bimolecular mechanism. Propylene production is hampered by hydrogen transfer reaction as it consumes the olefins generated by the catalytic cracking. This hydrogen transfer is 


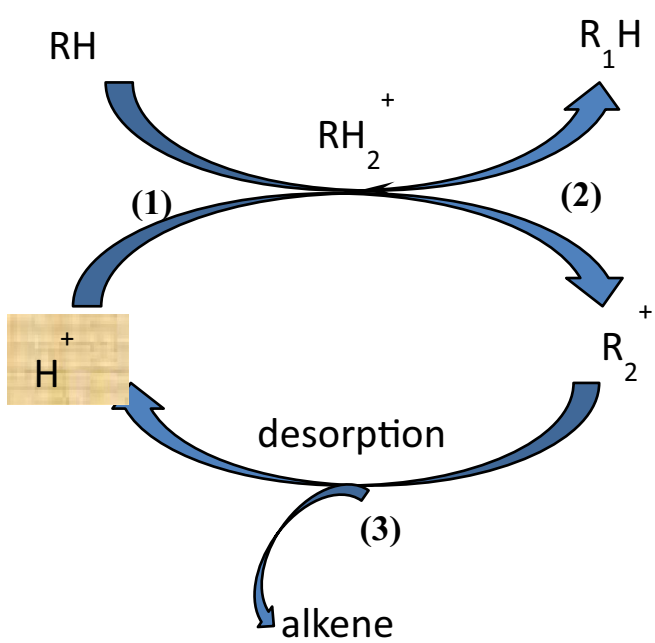

Monomolecular Mechanism

Fig. 8 Illustration of cracking mechanism

generally known to have a bimolecular reaction and it depends on the acidity of the catalyst, contact time and reaction temperature.

\section{Conclusions}

The results from these experiments show that propylene yield depends on the naphtha fraction being used as feed. LCN which contains a high percentage of olefins showed high reactivity and gave the highest propylene and light olefin yields, while HCN which is made up of mostly aromatics was the least reactive naphtha fraction. For straight run naphtha, HSRN showed a higher reactivity compared to LSRN. This is because, LSRN is made up of mainly $\mathrm{C}_{5}-\mathrm{C}_{6}$ molecules and are difficult to crack compared to HSRN which is made up of mainly $\mathrm{C}_{6}-\mathrm{C}_{11}$.

The results from this study further provide a guideline for processing naphtha fractions under high severity conditions for the production of light olefins. This will require the fine tuning of the catalyst system and reaction conditions to maximize the yields of light olefins.

Open Access This article is distributed under the terms of the Creative Commons Attribution 4.0 International License (http://crea tivecommons.org/licenses/by/4.0/), which permits unrestricted use, distribution, and reproduction in any medium, provided you give appropriate credit to the original author(s) and the source, provide a link to the Creative Commons license, and indicate if changes were made.

\section{References}

1. Brookes T (2012) New Technology developments in the petrochemical industry-refinery integration with petrochemicals to

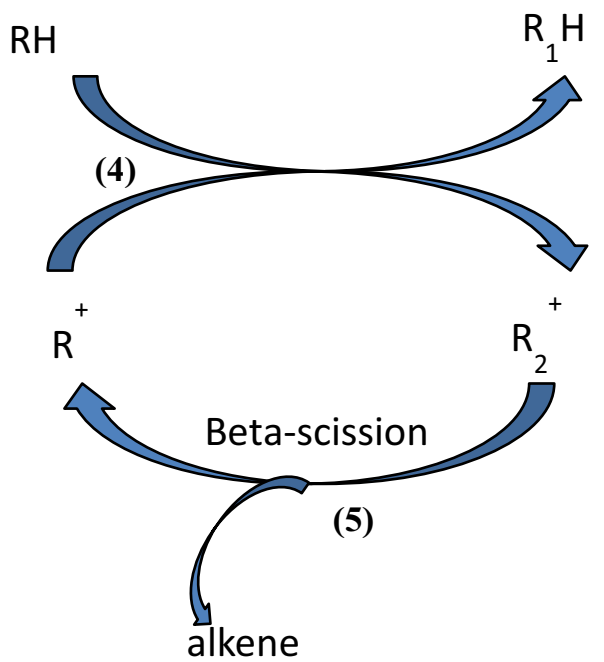

Bimolecular Mechanism

achieve higher value uplift in Egypt Petrochemicals Conference, Cairo-Egypt

2. Hyde B (2012) Light Olefins Market Review. In Foro Pemex Petroquimica, Mexico

3. Akah A, Al-Ghrami M (2015) Maximizing propylene production via FCC technology. Appl Petrochem Res 5(4):377-392

4. DOWNFLOW CONCURRENT CATALYTIC CRACKING. PHILLIPS PETROLEUM CO, US: United States

5. Triantafillidis CS et al (1999) Performance of ZSM-5 as a fluid catalytic cracking catalyst additive: effect of the total number of acid sites and particle size. Ind Eng Chem Res 38(3):916-927

6. Zhao X, Harding RH (1999) ZSM-5 additive in fluid catalytic cracking. 2. effect of hydrogen transfer characteristics of the base cracking catalysts and feedstocks. Ind Eng Chem Res 38(10):3854-3859

7. Zhao X, Roberie TG (1999) ZSM-5 additive in fluid catalytic cracking. 1. effect of additive level and temperature on light olefins and gasoline olefins. Ind Eng Chem Res 38(10):3847-3853

8. Aitani A, Yoshikawa T, Ino T (2000) Maximization of FCC light olefins by high severity operation and ZSM-5 addition. Catal Today 60(1-2):111-117

9. Degnan TF, Chitnis GK, Schipper PH (2000) History of ZSM-5 fluid catalytic cracking additive development at Mobil. Microporous Mesoporous Mater 35-36:245-252

10. den Hollander MA et al (2002) Gasoline conversion: reactivity towards cracking with equilibrated FCC and ZSM-5 catalysts. Appl Catal A 223(1-2):85-102

11. Corma A et al (2004) Different process schemes for converting light straight run and fluid catalytic cracking naphthas in a FCC unit for maximum propylene production. Appl Catal A 265(2):195-206

12. Abul-Hamayel MA, Aitani AM, Saeed MR (2005) Enhancement of propylene production in a downer FCC operation using a ZSM-5 additive. Chem Eng Technol 28(8):923-929

13. Arandes JM et al (2009) HZSM-5 zeolite as catalyst additive for residue cracking under FCC conditions. Energy Fuels 23(9):4215-4223

14. Lee J et al (2013) Catalytic cracking of C5 raffinate to light olefins over lanthanum-containing phosphorous-modified porous ZSM-5: effect of lanthanum content. Fuel Process Technol 109:189-195 
15. Shimada I et al (2015) Increasing Octane value in catalytic cracking of $\mathrm{n}$-hexadecane with addition of *BEA type zeolite. Catalysts 5(2):703

16. Haag WO, Lago RM, Weisz PB (1981) Transport and reactivity of hydrocarbon molecules in a shape-selective zeolite. Faraday Discuss Chem Soc 72:317-330

17. Wallenstein D, Harding RH (2001) The dependence of ZSM-5 additive performance on the hydrogen-transfer activity of the REUSY base catalyst in fluid catalytic cracking. Appl Catal A 214(1):11-29

18. Zhongqing L et al (2003) Cracking behavior of MCM-22, ZSM-5 and Beta as FCC catalyst additives. Prepr Pap Am Chem Soc Div Fuel Chem 48(2):714

19. Brooks R (2013) Modeling the North American market for natural gas liquids. In 32nd US Association of Energy and Economics (USAEE) Conference, Anchorage, 28-31 July

20. Cheng WC, Rajagopalan K (1989) Conversion of cyclohexene over Y-zeolites: a model reaction for hydrogen transfer. J Catal 119(2):354-358

21. Zhang J et al (2013) Synergistic process for coker gas oil catalytic cracking and gasoline reformation. Energy Fuels 27(2):654-665

22. Bastiani R et al (2013) Application of ferrierite zeolite in higholefin catalytic cracking. Fuel 107:680-687
23. Wielers AFH, Vaarkamp M, Post MFM (1991) Relation between properties and performance of zeolites in paraffin cracking. J Catal 127(1):51-66

24. Wang G, Xu C, Gao J (2008) Study of cracking FCC naphtha in a secondary riser of the FCC unit for maximum propylene production. Fuel Process Technol 89(9):864-873

25. Corma A et al (2005) Light cracked naphtha processing: controlling chemistry for maximum propylene production. Catal Today 107-108:699-706

26. Kotrel S, Knözinger H, Gates BC (2000) The Haag-Dessau mechanism of protolytic cracking of alkanes. Microporous Mesoporous Mater 35-36:11-20

27. Buchanan JS, Santiesteban JG, Haag WO (1996) Mechanistic considerations in acid-catalyzed cracking of olefins. J Catal 158(1):279-287

28. Rahimi N, Karimzadeh R (2011) Catalytic cracking of hydrocarbons over modified ZSM-5 zeolites to produce light olefins: a review. Appl Catal A 398:1-17

29. Komatsu T (2010) Catalytic cracking of paraffins on zeolite catalysts for the production of light olefins, in 20th annual SaudiJapan symposium catalysts in petroleum refining \& petrochemicals. Dhahran, Saudi Arabia 